\title{
Is there an information age in the whole developmental stages of the substance civilization of human society?
}

\author{
Zhang Bangwei \\ College of Physics, \\ Hunan University, China
}

\begin{abstract}
The "information age" and "information society" that have emerged in recent years and that have been clamored and overhyped by some people are not real existed. The entire historical facts of human society have proved that information and its communication and dissemination have existed since the advent of human beings. With the advancement of substance civilization, the highly developed information technology and means of communication are always accompanied, never left and interrupted. The six-stage theory proposed by the author for the development of material civilization in human society has theoretically ruled out the standard of information as the dividing stage of development of material civilization. Therefore either from the whole history facts or from the theoretical analysis there is no anyplace for the information age acting as a certain stage of the historical process of human social development.
\end{abstract}

Keywords: information, information age, information communication, matter, substance civilization, six-stage theory

\section{INTRODUCTION}

Regardless of whether you care or not, everybody is nearly met and dealt the "Information". Since the humankind has appeared in the world, information is accompanied with human beings and has never gone away, which will be discussed more in details below. Therefore, near nobody disagrees the importance of information. In addition, the key issue discussed in the paper concerns to that if the "information age" can be acted as a stage for the development of material civilization in human society, so it must be closely related with the information. Thus the issue discussed first in the paper is what information is, and how people recognize and define information.

Who and when named the Information Age first? It is difficult to say. However, regardless of whether you are willing or not, the mainstream trend in academia is that human society has entered the information age or the information society from a certain moment. Not considering the situation from media's buzz and propaganda, only accounting the numbers displayed by Google's academic and Baidu academic search websites and Elsevier and Springer databases respectively after entering the keyword "information age" ("information society"), they are $5,790,000(5,900,000), 319,000(356,000), 26,406(26,403), 1,600,005(1,344,175)$. It shows that the number of documents is quite large, and it can be seen what the mainstream tendency is. Of course, these

documents are not all directly describing and discussing the "information age" ("information society"), and most of them are only relevant, but they are sufficient to illustrate the mainstream tendency. Because there are too many documents, the rational values refer to two English and two Chinese books as examples: Gates (1995), Castells (2000), and Wang, X. D. (1997), Zhong, Y. X. (2002). The problem is that if you take a little more care, you will find that 
in these representative documents it is difficult to find out the theoretical description of why the "information age" ("information society") has only recently appeared, and generally speaking only discusses or describes what the "information age" ("information society") is, what its characteristics and manifestations are, how well it is, and etc. Except these four books, it must be to mention another book "Theories of the Information Society" (Webster, 2014). From this so clear title of the book, people naturally want to get obvious theoretical answers in the book about why the "Information Age" emerges at recent years, how do we distinguish between the "Information Age" and other societies (certainly there are not only one stage of human society but several stages), what are the standards for dividing the different stages of human societies, and what are the viewpoints about the whole historical facts that human beings use the information exchange and dissemination from emergence of human beings till today? Webster said that "Theories of the Information Society, the first edition of which was drafted in the early 1990s, set about related claims that a new world was coming into being largely on the back of technological breakthroughs. This was set to be a new 'weightless' economy, a 'flat' world that would overturn established ways of behaving, an epoch in which 'thinking smart' was at one with the emerging 'Information Society'. Editions two and three continued to engage with similar claims for technology's impact since it seemed that such claims for technology's effects could not be quietened." It seems from these claims of the book that the answers people wanted to obtained are difficult to get.

Can the "information age" (Information Society) really be able to stand up? In the author's opinion, it has been artificially instigated, because it has not received any strong facts and clear theoretical support, so it is completely untenable. Of course, this must be proved by finding conclusive facts and theoretical grounds.

It is interesting to note that, although the mainstream academic community is now so monolithic that it is difficult to find straightforward opposing articles, but a few opposing voices can be found in the literature. For example, as early as 1651, Hobbes (1651) opposed the mainstream consciousness in his book and raised objections. In addition, Headrick (2000) believed human demand for information is as old as humanity itself, and consequently confirmed using the facts from 1700-1850 that one should not look to name any single moment as the "dawn" of the Information Age, e.g. the Information Age began only yesterday with the computer or transistor.

The key points for the paper are to verify that why the information age cannot be acted as an age in the development stages for the material civilization of human society. These include three aspects at least. The first is to analyze the original occurs of information, and the different developed stages of information. Next is to illustrate the nature of information and information age. The third is to prove information cannot be acted as a dividing standard of the development stages of human substance civilization. As far as the author knows, all of these have not been discussed completely yet in the literatures, which are talked about in the paper for the first time.

\section{WHAT IS INFORMATION?}

There are a lot of papers and books to discuss such issue in the literatures. First, a typical example (Mingers and Standing, 2017) is discussed, and then several reports are selected for description to make more details for understanding. However, we don't want to mention all or most of them because it is not the task of the paper.

We mentioned that that paper is a typical example (Mingers and Standing, 2017) because it published in the very recent year (2017) and its title is"What is information? Toward a theory 
of information as objective and veridical". According to those two authors of the paper, even up to 2017 "there is still not an agreed and explicit conceptualization or definition of information" in the world. After they cited other author's results from literature survey, they made a conclusion further that there is no clear and accepted definition of information and that there is very little discussion of this in the literature. Rather, a variety of different, generally implicit, conceptions are in play. It is interesting to note that in one of the most rigorous attempts to define fundamental concepts -the deep structure model of Wand and Weber $(1990,1995)-28$ concepts are defined ${ }^{1}$, but information is not one of them. Of course, this situation is somewhat regrettable. Therefore, they developed and defined "a particular theory". They mean that "the information carried by signs and messages exists independently of its receivers or observers. The information carried by a sign exists even if the sign is not actually observed." Also they mean that "information must be true or correct in order to be information - information is truth-constituted. False information is not information, but misinformation or disinformation." It is interested to note that Hu Wengen (1992) have conducted statistics that there are more than 200 information definitions available in the literature. In other words, there is no unified information definition up today.

As for these two authors said that "False information is not information", it may be difficult to convince people. Why? False information is also made by somebody, or by some group of people, or by some institution such as a company, a school, or even an office from some government, which means that the origin either for correct or false information is the same, i.e. from some people. Why true or correct information can be called information but false information cannot be? What is the reason? On the other hand, one piece of information is correct or false should be appraised. Who can appraise it? Usually ordinary people cannot appraise it themselves because they have no enough time and energy to do that, and the specialized identification agency cannot do that for them except they pay much money to it. So, when someone received two pieces of information, one is correct, another is false, and then we must say that he/she received only one piece of information because another is false so is not information. Isn't it? In addition, near everybody easy to know that the false information is often deliberately created by the spies and secret service, and very few ordinary people may create wrong information for certain interests as well. Of course, this information cannot be called information. What are they called?

In 1948, in his paper of "A Mathematical Theory of Communication", Shannon (1948) wrote that "If the number of messages in the set is finite then this number or any monotonic function of this number can be regarded as a measure of the information produced when one message is chosen from the set, all choices being equally likely." Then, Shannon asked: "Can we define a quantity which will measure, in some sense, how much information is "produced" by such a process, or better, at what rate information is produced?" After some mathematical derivation, he proposed:

$$
\mathrm{H}=-\mathrm{K} \sum_{\mathrm{i}=1}^{\mathrm{n}} \mathrm{p}_{\mathrm{i}} \log \mathrm{p}_{\mathrm{i}}
$$

as the definition of information. He said that "Quantities of the form $H=-K \sum p_{i} \log p_{i}$ (the constant $\mathrm{K}$ merely amounts to a choice of a unit of measure) play a central role in information theory as measures of information, choice and uncertainty. $\mathrm{H}$ will be recognized as that of entropy as defined in certain formulations of statistical mechanics." That is to say that Shannon defines information as the entropy in the statistical physics. Here $\mathrm{K}$ is a positive constant, $\mathrm{p}_{\mathrm{i}}$ is the probability of a system being in cell $i$ of its phase space. How do we measure information? It uses bit. According to Shannon (1948), "The choice of a logarithmic base corresponds to the 
choice of a unit for measuring information. If the base 2 is used the resulting units may be called binary digits, or more briefly bits, .... A device with two stable positions, such as a relay or a flip-flop circuit, can store one bit of information. $\mathrm{N}$ such devices can store $\mathrm{N}$ bits, since the total number of possible states is $2^{\mathrm{N}}$ and $\log _{2} 2^{\mathrm{N}}=\mathrm{N}$." Therefore, Shannon was the first user to use bit as the unit for measuring information.

As Shannon (1948) pointed himself in the beginning of his paper, Nyquist (1924) and Hartley (1928) published "important papers", building "a basis for such a theory (a general theory of communication - the author)". Of course, Shannon (1948) has extended "the theory to include a number of new factors, in particular the effect of noise in the channel, and the savings possible due to the statistical structure of the original message and due to the nature of the final destination of the information." (Shannon, 1948). So that, a formula for measuring the average amount of information is given by Shannon, realizing the leap of communication science from qualitative stage to quantitative stage as mentioned above. Why Shannon said that Nyquist and Hartley built a basis of information theory? For Nyquist (1924), he derived a formula of the speed of transmission of intelligence $\mathrm{W}$ as

$$
\mathrm{W}=\mathrm{K} \log \mathrm{m}
$$

where $\mathrm{m}$ is the number of current values, and, $\mathrm{K}$ is a constant. According to Nyquist (1924), the meaning of the speed of transmission of intelligence is that the number of characters, representing different letters, figures, etc., which can be transmitted in a given length of time assuming that the circuit transmits a given number of signal elements per unit time. And for Hartley (1928), he also derived his formula for the amount of information associated with $n$ selections:

$$
\mathrm{H}=\mathrm{n} \log \mathrm{s}
$$

$\mathrm{s}$ is the number of possible symbols available at each selection in a transmission, $\mathrm{n}$ is the number of selections of primary symbols. Equation (3) shows that the practical measure of information is the logarithm of the number of possible symbol sequences. Pierce (1973) evaluated Hartley's work as: "his idea of defining the quantity of information as the logarithm of the number of symbols seems very modern, but its success in elucidating knotty problems was not great. It is Shannon's feeling, and mine, that Nyquist's work was more fruitful." In addition, Rioul and Magossi (2014) also evaluated Hartley's work. They belived that some "historical" statements in the literature for the relationship between "Hartley's rule" and Shannon's formula are somewhat wrong, because their careful calculation shows that "Hartley's rule" in fact coincides with Shannon's formula. They found that this mathematical coincidence by deriving the necessary and sufficient conditions on an additive noise channel such that its capacity is given by Shannon's formula and construct a sequence of such channels that makes the link between the uniform (Hartley) and Gaussian (Shannon) channels.

In addition, Szilard in 1929 in his famous paper "Uber die Entropieverminderung in einem thermodynamischen System bei Eingriffen intelligenter Wesen" published his information definition i.e. information is entropy (Szilard, 1929). Szilard wanted to understand the "Maxwell's demon" and how much energy the demon would consume in its operations, so he designed a thermodynamic "gedanken experiment". Such experiment was called Szilard's engine later in the literature. It employs an intelligent being operating the heat engine with a single molecule. The molecule is originally placed in a box, free to move in the entire volume. Then a partition is inserted to divides the box into two equal parts. At this point the Maxwell's demon measures in which side of the box the molecule is and records the result. The Maxwell 
demon uses the information to replace the partition with a piston and couple the latter to a load. The one molecule gas is put in contact with a reservoir and expands isothermically to the original volume. During the expansion the gas draws heat from the reservoir and does work to lift the load. Apparently the device is returned to its initial state and it is ready to perform another cycle whose net result is again full conversion of heat into work, a process forbidden by the second law of thermodynamics. It should be pointed out that the above description has missed an important point: the demon needs to erase the information stored in his mind for the process to be truly cyclic while the gas in the box has returned to its initial state. This is because the information in the brain of the demon is stored in physical objects and cannot be regarded as a purely mathematical concept! Otherwise, if Szilard's model engine could indeed generate useful work, in the way described above at no additional expense of free energy, it would constitute a perpetuum mobile, as it delivers mechanical work from an (infinite) heat reservoir with no apparent temperature difference. To fend off this threat to the thermodynamic irreversibility, Szilard has noted that, "If we do not wish to admit that the Second Law has been violated, we must conclude that ... the measurement ... must be accompanied by a production of entropy." The mean value of the quantity of entropy $S_{A}$ and $S_{B}$, per measurement, has been calculated by Szilard:

$$
\mathrm{S}_{\mathrm{A}}=-\mathrm{k} \log \mathrm{p}\left(\mathrm{T}_{0}\right) ; \mathrm{S}_{\mathrm{B}}=-\mathrm{k} \log \mathrm{q}\left(\mathrm{T}_{0}\right)
$$

where the $\mathrm{p}(\mathrm{T})$ and $\mathrm{q}(\mathrm{T})$ are the probabilities which are in the lower or upper state respectively because Szilard only evaluated these expressions for the very simple ease, where the body which he used has only two energy states, lower and a higher state. $\mathrm{T}_{0}$ is the temperature of the heat reservoir. Obviously the meaning of equation (4) is the same as that in equation (1) which means that Szilard not only correctly defines the quantity known today as information, which has found a wide use in the work of Claude Shannon and others in the field of communication science. The history fact indicates evidently that Shannon is not but Szilard is the real first man to define information using the entropy. In addition, though Shannon's paper (Shannon, 1948) was published later than that of Szilard (1929) for 19 years, however Shannon's paper did not cited the paper by Szilard.

When Shannon proposed his definition of information in 1948 (Shannon, 1948), Wiener in 1948 (Wiener, 1961) proposed his own definition of information as well in the same year in his famous book 《Cybernetics》 . Not only one but several place in the book you can found the description of information by Wiener. For example, in the Introduction of the book (P.11), he wrote that "The notion of the amount of information attaches itself very naturally to a classical notion in of statistical mechanics:-that of entropy. Just as the amount of information in a system is a measure of its degree of organization, so the entropy of a system is the measure of its degree of disorganization; and the one is simply the negative of the other. This point of view leads us to a number of considerations concerning the second law of thermodynamics, and to a study of the possibility of the so-called Maxwell demons." In the Chapter 3 of the book (P. 62), he wrote as well that "The quantity we here define as amount of information is the negative of the quantity usually defined as entropy in similar situations. The definition here given is not the one given by R. A. Fisher for statistical problems, although it is a statistical definition; and can be used to replace Fisher's definition in the technique of statistics." Especially in the last paragraph of the Chapter 5 of the book (P. 132), he said that "Information is information, not matter or energy. No materialism which does not admit this can survive at the present day." It is obviously that, the first two descriptions are similar, but for the third one, people are difficult to image that it is as similar as the first two descriptions, at least needing explanation more in details. However, Wiener himself did not give such explanation, in addition, he neither did describe the third description more in detail, nor any explain of that. It seems that something is 
left just for people to image. Because he did say information is not matter or energy but did not say what is it? Such situation caused a number of authors to analyze or to image this issue, putting forward their own opinions or conjectures. I do not list all of these authors and their papers or books here because it is rather long, but just use 1, 2 typical examples to explain it.

Most of these authors criticize such definition. For example, Faucher (2013) in his book said:"This statement leaves us in a bit of a quandary: if information is not matter or energy, what is it? Is it a kind of ether, a phlogiston, a spirit-force? Not quite. Wiener does not raise information to the state of Mind either. It is still somewhat material, a "stuff" of sorts, but is not matter (i.e., not physical as such)."Also, Logan (2012) wrote that"The question that arises is whether or not there is something intrinsic about information or is it merely a description of or a metaphor for the complex patterns of behavior of material things. Does information really control matter or is information purely a mental construct based on the notion of human communication through symbolic language, which in turn is a product of conceptual thought as described in Logan, (2007)?"Zhong Yixin, (2002) disagreed such opinion of Wiener as well in his book, he wrote that "However, what is the message that "it's not matter, it's not energy"? Is it spirit? Wiener did not say it himself, and others could not be sure. Of course, the argument that "information is knowledge" or "information is intelligence" regard information as a spirit, because knowledge and intelligence are things in the minds of people."By the way, Zhong Yixin also criticize obviously the point of view that Information is a matter from А. Берг (А. Берг used"information field"to represent it) in his book. These citations show that the common points of view from the mainstream academic community of information sciences do not believe that information is a matter.

From the statistical considerations and the definition of the measure of information, Brillouin, (1953) proves directly that "information" corresponds to a negative term in the final entropy of a physical system. He uses the equation below to represent it:

$$
\text { Information=negentropy (negative entropy) }
$$

From Encyclopedia Britannica Online, one can find that "In popular usage, the term information refers to facts and opinions provided and received during the course of daily life: one obtains information directly from other living beings, from mass media, from electronic data banks, and from all sorts of observable phenomena in the surrounding environment. A person using such facts and opinions generates more information, some of which is communicated to others during discourse, by instructions, in letters and documents, and through other media."

We don't want to continue to quote like this; and from the above citations and analysis, it can be seen evidently that all these definitions of information are different, often overlapping and sometimes conflicting. Why? The concepts from various proposers are not the same. Their angles and ways of looking at the problem are not only the same. In addition, the issue is complicated. It is not easy to catch the nature. It is somewhat similar to what is said in the old story of "Blind men sizing up the elephant."

Considering the above situation, we want to propose ourselves definition of information. We don't think it is the best one, but it is really easy to understand the nature and the meaning because people are difficult really to catch the meanings from many existed definitions of information. Our definition of information is that information is not a substance but needs to have a physical carrier, which sends, communicates and stores messages, knowledge, data and intelligence directly or indirectly through human's expressions or hints, things they write or 
create as well as tools or media they used, so as to make people to perceive insight or excitement, worriment or angry, calm or indifference.

\section{INFORMATION TECHNOLOGY AND ITS COMMUNICATION ARE ALWAYS ACCOMPANIED BY HUMAN BEINGS}

Information technology and its communication have always been accompanied by human beings. They have emerged with the emergence of human beings, developed with the development of human beings, from nothing, from low to high, never stopped, never left humans. Therefore, to understand and describe the entire and complete history of information technology development, even though that the content of the occurrence and development of information in each stage is not very detailed, but also can prove from objective historical facts whether the information society exists or not. If in the whole history of human development information is always accompanied, never left, and never interrupted, then the history of information is as long as the entire human history. Then the entire human society is the information society. How can the so-called information society emerge from a certain time because of the emergence of a certain information technology? Regrettably, although there are many articles and books involved in information, it is difficult to find out that the entire history of human information can be truly discussed and described.

For example, there is a good book of 《The information: a history, a theory, a flood》 by Gleick (Gleick, 2011), but it is not a real book of the history of information. From the book people are rather difficult to understand a rather complete history of information because the stories are more than history in it. Similarly there is a good paper of 《History of information science》 (Buckland, \& Liu, 1995), the two authors said that "We have treated IS (information science) inclusively in two senses. First, we include specialized applications areas, such as archival, library, and corporate information services as specialties within a broad view of IS rather than specialties outside of it. Second, we agree with VAKKARI (1994) that it is misguided on theoretical grounds (as well as difficult in practice) to separate the theory of library science and of documentation from that of IS." That is to say that that paper is still not mentioned the whole history of information as we want. Therefore, the author has to write the history of the entire information communications of human beings. Of course, we do not want to describe the history of information for human society in detail, but just to sketch out the whole information history for human beings completely and comprehensively. At the beginning, such discussion and description was including in this paper, however it caused the length of paper was too long, so a separated paper was written (Zhang, 2019), and here the author is just to cite the contents briefly. Two parts of the information histories are discussed separately: prehistory and historically recorded periods. Every part is separated according to several succeeded stages for description. There are six stages and technologies in the prehistory:

The first is visual transmission. (Bradshaw rock paintings have found c. 15,000 BC.)

The second is sound transmission. (Primitive people used mouth, bamboo flute, wooden drums, etc to transmit information.)

The third is optical transmission. (Before BC 6000 ancient Chinese people have known how to get fire with drilling wood, then using fire and smoke to transmit information.)

The fourth one is language transmission. (An origin of modern languages predating the African exodus 50,000 to 70,000 years ago, human ancestors used language to communicate very early.) 
The fifth is symbol transmission. (Early at the beginning of Xia Dynasty at BC 2070, Chinese ancients discovered oracle, and the text communication must very early.)

The sixth is postal service in ancient times. ("postal service" was founded in China at BC 1400.)

There are seven stages and technologies after entered into the stage with historical records:

The seventh is writing communication. (In the early age of Western Han Dynasty starting from 206 BC), Chinese began to use paper.)

The eighth is printing communication. (Blocking Printing occurred at Ten years of Zhenguan (636 AD) in the Han Dynasty, China.)

The ninth is telegraph and telephone transmission. (Chappe telegraph was discovery first in 1791. Morse in 1837 finally devised the Morse code. In 1844 Manzetti first proposes the idea of an electric "speaking telegraph. Meucci created the first model of a telephone in Italy in 1834. The modern telegraph and telephone are the result of work of many people.)

The tenth is vacuum tube and transistor. (Diode in1905 and Triode in 1907. Transistor was invited by Schockley, Bardeen and Brattia in 1947.)

The eleventh is computer network transmission. (1946, Mauchly and Eckert developed the computer ENIAC I. The first practical ICs were invented by Kilby and Noyce, and the first IC computer made by Texas Instruments by 1961.)

The twelve is mobile communication. (Stubblefield in 1902 invented wireless telephone first in the world. The real mobile phone was made by Cooper in 1973.)

The thirteen is internet communication. (In the 1950s-1960s, there were various simple computer networks appeared in the word. The real computer network was the first four nodes of the ARPANET created by the commission of the US Department of Defense in 1969.)

For the exchange of information and communication between human beings from the initial era of the past, until today's highly developed internet communication, in accordance with the development of substance civilization, we have divide it into 13 stages or ways (of which 6 were prehistoric, 7 were in the time of historically recorded periods) for discussion. Though such description and discussion were not very detailed, but were quite comprehensive. From these solid facts several conclusions can be easy drawn.

(1) All historical facts show that from the very beginning of human beings, information and its communication and dissemination have emerged, always accompanied by human beings, never left, never interrupted.

(2) Along with the development of human material civilization, information and its transmission are also accompanied by development from low level to advanced level.

(3) In the course of development, when human beings feel that information and its transmission are not very compatible, there must be some people, intentionally or unintentionally, individually or in small organizations to develop information and its transmission mode, and make it adapt again. Such a period of time is uncertain, but human society has not had any historically recorded chaos.

(4) Information and its exchange and dissemination are necessary conditions for human beings to emerge, survive and develop. Humanity has survived for several million years, with a history of civilization of 5,6 thousand years. Without the exchange and 
dissemination of information, people are absolutely an isolated individual. Human beings cannot be produced, and it is impossible to survive and develop. Information and its communication and dissemination are as necessary as air and water to human beings, and cannot be left without it any moment. Each king of animal in the animal kingdom has its own information exchange and dissemination, otherwise it will be destroyed. The animal world is still the same, not to mention the highly developed human beings, who can make themselves without any information exchange and dissemination, and become individuals who are absolutely isolated?

(5) All we described the historical facts that about the whole information and its communication and dissemination for the emergence and development of mankind, completely refutes all at once the notion or theory that the occurrence of information age (or information society) results from the advent of computers or the internet or any other invention. As long as we still respect the history, but also face the facts, it is pale and powerless to say that the invention of certain artifacts has led to the emergence of the information society. Information and its dissemination have followed mankind from the very beginning, never leaving, but only gradually evolving from the lower to the higher.

Then why someone has proposed that after the invention of computers or the Internet, human society has entered into an information age, they shouted loudly in the world, and there are still many authors following suit? Let's try to analyze it simple.

The first is that they themselves are not studying and looking for the entire history of information that is closely following human development and its spread. Even if they read the historical descriptions from others, they have to think them carefully. This argument is particularly clear when comparing the contents and conclusions of two books. One is "The Information Age: Economy, Society and Culture" by Castells (2000), and the other is "The Information: A History, A Theory, A Flood" by Gleick (2011). The former basically does not involve the occurrence and development of information technology that has been followed by human society as described above, indicating that the author does not care about the history of the development of information, so the title of the book is marked obviously as "The Information Age." The latter basically writes about the history of the development of information, though its description of information histories is not so formal, not completely and extensively, even the terms "information society" and "information age" are hard to see in the book. In addition, Gleick (2011) also wrote that "The alphabet was a founding technology of information. The telephone, the fax machine, the calculator, and, ultimately, the computer are only the latest innovations devised for saving, manipulating, and communicating knowledge. ... We know about streaming information, parsing it, sorting it, matching it, and filtering it. ... so we see information in the foreground. But it has always been there. It pervaded our ancestors' world, too, taking forms from solid to ethereal, granite gravestones and the whispers of courtiers. The punched card, the cash register, the nineteenth-century Difference Engine, the wires of telegraphy all played their parts in weaving the spider web of information to which we cling. Each new information technology, in its own time, set off blooms in storage and transmission. From the printing press came new species of information organizers: dictionaries, cyclopaedias, almanacs-compendiums of words, classifiers of facts, trees of knowledge. Hardly any information technology goes obsolete. Each new one throws its predecessors into relief." The meaning of this rather longer paragraph by Gleick indicates obviously in agreement with our opinions analyzed above: information always exists since the very begging in human kind, every information technology either the old The Beacon Tower or the newest and advanced internet is the same from the nature no any difference, and claiming 
that "human beings have entered the information age" is violated all historical facts, without basis and untenable.

As for the Chinese books, two books are also cited as examples. They all firmly believe in and promote the "information age" and "information society." One is Zhong Yixin's book "The Principles of Information Science" (Zhong, Y. X., 2002). It claims that "human beings have entered the information age", "the entire era is called the "information age", and the entire society has also evolved toward the "information society." The other is the "World Map of the Information Age" written by Wang Xiaodong (Wang, X. D., 1997), which is also believed that the information age (or the information society) has entered human society since some term. Neither of the two books deals with the history of the emergence and development of information in human society, and therefore all of their claims that human society has entered the "information age" have become castles in the air, without any supports by the historical facts.

The second is that the age and society are big words, which should be a long period of human society. Only by carefully studying and analyzing the whole process of substance civilization of the whole human society and having its own theoretical description (of course, it is not impossible to analyze it by the theory proposed by others), one can be able more accurately to name all or one of them. Otherwise, it will be difficult to avoid blindness or following the statements of others. Most of the authors who put forward this kind of "information age" in their articles or books may have problems in this respect.

The third is that because many articles and books are talking about the information age, so some people may follow the trend. Such situation may cannot be ruled out.

The last point is that the vicious speculation of the media. After the computer and the network were successively invented, the media, under the excessive noise of some people in the industry, has spared no effort to hype viciously. It seems that except these newly invented information technologies, human beings have never had any other information tools. Human society seems that never have lived an appropriate information life and service. This of course is totally different from the fact that so many information technologies and means we discussed above. Such kind type of media hype has actually been opposed and criticized before. Early in the 17th century, Thomas Hobbs resisted the new media hype of his time. He said in his book (Hobbes, 1651) "The invention of printing, though ingenious, compared with the invention of letters, is no great matter." Gleick (2011) cited the words of Hobbes also, indicating that he agrees with this point of view.

\section{INFORMATION CANNOT BE ACTED AS THE DIVIDING STANDARD OF THE DEVELOPMENT STAGES OF HUMAN SUBSTANCE CIVILIZATION}

More than ten years ago, during the author wrote his book "Physical fundamental of nanomaterials" (Zhang, B. W., 2009) he found that there were very few literatures about studying the development stages of human substance civilization which he didn't know what the reasons were. In first chapter (the introduction) of the book, he preliminary expounded that why we must use a typical material as the standard for the dividing the development stages of human substance civilization. Later on he has studied this subject because it is interest to him though it is not so closed to his original research field. Therefore he published three framework papers (Zhang, B. W. and Yan, Y. J., 2011, Yang Y. J. and Zhang B. W., 2011, Zhang, B. W., 2012), two of them were cooperated with another author. In these papers, he proposed a six age theory for the development of the substance civilization of human society. The main points of the theory include: it bases on the point of view of the tool of production 
but not from the production relations; the standard for dividing the stages of the substance civilization of human society is the typical materials of manufactured tools and devices, and the typical materials must be made by humans themselves; up to date human substance civilization can be separated six stages according to the standards, and the present substance of civilization in human society has entering into the nanomaterials age. Here he only uses the theory and standards to discuss the issue that why information cannot be acted as the dividing standard for the development stages of human substance civilization, so the information age cannot not be existed from the theoretical view point.

According to the theory mentioned above, up today there are only six typical materials: Stone, Bronze, Iron, Steel, Silicon and Nanomaterials. Therefore, there are six ages in the development of substance civilization of human society. Of course, there is no place for the Information Age.

Why information cannot be acted as a typical material for dividing standard of the development stages of human substance civilization?

Firstly, the issue we discussed is the development stages of human substance civilization, as a standard of the development stages of human substance civilization must be a matter, any kind of non-matter cannot be acted as such a standard definitely. According to the some specialist books and papers which concentrated to discuss the nature and/or properties of matter e.g. (Grolier Incorporated (1990), The Editors of Encyclopedia Britannica (1998), Ball D. W. (2015), Volk, G. (2002), Chan, T. U. (2006)), though there is no single universally agreed scientific meaning of the word "matter", but it is easy to understand that matter is the raw material of the universe. Stars, planets, mountains, oceans, and atmospheres are all made of matter. So are plants and animals-including humans and every material thing we have ever produced.

All matter is made of something, even if it looks like nothing. As the progress of scientific research, our understanding of matter is getting deeper and deeper, and the definition of matter is changed accordingly. In the stage of atomic level, the definition of matter is that matter is made up of atoms. Deeper than the level of atoms, the definition of matter can be that matter is made of positively charged protons, neutral neutrons, and negatively charged electrons (de Podesta, 2002). As people reorganized the scale of elementary particles, the definition of matter is that ordinary matter is everything that is composed of quarks and leptons, or ordinary matter is everything that is composed of any elementary fermions except antiquarks and antileptons (Povh, et al., 2004, Carithers and Grannis, 1995, Tsan, 2006). Then, Can information be defined in this way? Especially the definition can be progressed as the people's understanding future deepened? No! Cannot, because information is not a matter.

Matter reveals itself through properties, i.e. as a matter, it must have common natures and attributes. There are many common properties for the matter; it is no necessary to discuss those details here, but just using the states of matter to illustrate. Near everybody knows that matter has three states: gas, liquid and solid as the reduction of temperature. As people's understanding goes deeper, plasma state was found at the very high temperature, and the state of Bose-Einstein condensates exists at very low temperature. Though the later two states of matter may not be known to everybody but they are exited really. In addition, most substances can transition between these states when the external physical conditions are changed e.g. based on the amount of heat the material absorbs (or loses). If one says information is a matter, then information must be existed in such five states which we have known up today. Also information should be transmitted between these states when the external physical conditions are changed. Who has seen that information has such states and such transition 
between the states? We can definitely say that no anyone has seen those because information is not a matter.

Secondly, according to the six age theory for the development of the substance civilization of human society, the dividing standards must be a kind of materials. If information is a real material, what kind of materials it belongs? Ingredients, clothing materials, medical materials, stationery materials, communication materials ‥? Of course, information is not belonged to anyone kind of these substances! That is to say, information is not a real substance.

Any kind of materials can be used to manufacture the tools and devices. This is the common sense of human society since the Stone Age, for which few people don't know. If information is a real material, what tools and devices you can make by using it? Who has seen any tools or devices in the world made by information? Please tell only one piece as example. In fact no one can reply it! The reason is that information is not a material.

Thirdly, not only the dividing standards must be a kind of materials for the development of the substance civilization of human society according to the six age theory, but must be a typical material. Since information cannot be a kind of materials as above, it must not a typical material definitely.

Therefore, from the point of view of our proposed theory we analyzed above that information cannot be a matter, it is not a kind of materials, and definitely is not a typical material. In a word, information cannot be acted as the dividing standard of the development stages of human substance civilization. Therefore, there is no age of information definitely in the development stages of substance civilization of human society.

\section{CONCLUSIONS}

The aim of this paper is to address that can information age be existed in the whole developmental stage of the substance civilization in human society? We discussed and analyzed the issue form three aspects: the nature of information, the whole development histories of information in the human development and the theory for the development stages of human substance civilization. The answer is no! There is no anyplace for information age in the whole developmental stages of the substance civilization in human society.

What is information? There are too many papers and books discuss this problem. Though "there is still not an agreed and explicit conceptualization or definition of information" (Mingers and Standing, 2017) in the world, and according to the statistics (Note 1), there are more than 200 information definitions available in the literature, however, the common points of view from the mainstream academic community of information sciences do not believe that information is a matter. Of course, though information is not a matter but it relates with matter, just as said in our definition of information that information is not a substance but needs to have a physical carrier.

Comprehensive history of information development for human society has been discussed and analyzed in the paper though every item is not so detail. According to the all historical facts from the very beginning of human beings the conclusion is evidently that information and its communication and dissemination have emerged with occurrence of human beings, always accompanied by human beings, never left, and never interrupted. The notion or theory that the occurrence of information age (or information society) results from the advent of computers or the internet or any other invention is opposite to the whole history facts for the human society. 
According to the theory proposed by the author, up today there are only six typical materials: Stone, Bronze, Iron, Steel, Silicon and Nanomaterials. Information cannot be acted as a standard for dividing the development stages of substance civilization for human society because information is not a matter, is mot a kind of material, and is not even more a typical material which all do not meet the necessary conditions for a standard of dividing standard of substance civilization. Therefore, up to present there are only six ages in the development of substance civilization of human society. Of course, there is no place for the Information Age.

\section{References}

Ball, D. W. (2015). The Nature of Matter: Understanding the Physical World, Virginia: Chantilly.

Brillouin, L. (1953). “The Negentropy Principle of Information”, Journal of Applied Physics 24: 1152-1163.

Buckland, K. M., and Liu, Ziming, (1995). “History of Information Science”. Annual Review of Information Science and Technology (ARIST) 30: 385-416.

Carithers, B. and Grannis, P. (1995). “Discovery of the Top Quark”, Beam Line. SLAC National Accelerator Laboratory, 25 (3): 4-16.

Castells, M., (2000). The Information Age: Economy, Society and Culture (V.1 Rise of the Network Society, V.2 The Power of Identity, V.3 End of Millennium), Malden, MA : Blackwell Publishers Ltd.

Chan, T. U. (2006). “What Is a Matter Particle?” International Journal of Modern Physics E 15 (1): 259-272. de Podesta, M. (2002). Understanding the Properties of Matter (2nd ed.). CRC Press. p. 8.

Faucher, K. X. (2013). Metastasis and Metastability, A Deleuzian Approach to Information (pp.. 8-11), The Netherlands: Sense Publishers.

Gates, B. (1995). The road ahead, Williams H. Gates III.

Gleick, J. (2011). The Information: A History, A Theory, A Flood, New York: Pantheon Books.

Grolier Incorporated (1990). Matter, Encyclopedia Americana, V.18, p.295. New York.

Headrick, D. R. (2000). When Information Came of Age: Technologies of Knowledge in the Age

of Reason and Revolution, 1700-1850, Oxford/New York: Oxford University Press.

Hartley, R. V. L. (1928). “Transmission of Information”, Bell System Technical Journal 7 (3): 535-563.

Hobbes, T. (1651). Leviathan, (ch. 4, P.23) London: Oxford University Press.

Hu Wengen. (1992). Information, Brain and Conscioueness (p.207), Beijing: China Social Sciences Press.

Logan, R. K. (2007). The Extended Mind: The Origin of Language and Culture Toronto: University of Toronto Press.

Logan, R. K. (2012). "What Is Information?: Why Is It Relativistic and What Is Its Relationship to Materiality, Meaning and Organization", Information 3: 68-91.

Mingers, J. and Standing, C. (2017). "What is Information? Toward a Theory of Information as Objective and Veridical", Journal of Information Technology 33 (2): 85-104.

Nyquist, H. (1924). "Certain Factors Affecting Telegraph Speed”, Transactions of the American Institute of Electrical Engineers 43: 412 - 422.

Pierce, J. R. (1973). “The Early Days of Information Theory, Invited Paper”. IEEE Transactions on Information Theory IT-19 (1): 3-8.

Povh, B., Rith, K., Scholz, C., Zetsche, F. and Lavelle, M. (2004). Part I: Analysis: The building blocks of matter. Particles and Nuclei: An Introduction to the Physical Concepts (4th ed.). Germeny: Springer.

Rioul, Olivier and Magossi, José Carlos. (2014). “On Shannon’s Formula and Hartley’s Rule: Beyond the Mathematical Coincidencey”, Entropy 16: 4892-4910.

Shannon, C. (1948). “A Mathematical Theory of Communication”, The Bell System Technical Journal 27: 379-423, 623-656.

Szilard, L. (1929).“On entropy reduction in a thermodynamic system by interference by intelligent subjects”,

Zeitschrift fuer Physik 53: 840-856. 
The Editors of Encyclopedia Britannica (1998). Matter, Encyclopedia Britannica, V.11, p. 14. London: Encyclopedia Britannica.

Tsan, U. C. (2006). “What Is a Matter Particle?” International Journal of Modern Physics E 15: 259-272.

Volk, G. (2002)."A Matter of Definition”, Saturday Evening Post 81 (2): 311-315.

Wang, X. D. (1997), World Map of Information Age, Beijing: Press of Renmin University of China, China.

Webster, F. (2014). Theories of the Information Society, This fourth edition, Oxon: Abingdon Milton Park.

Wiener, N. (1961). Cybernetics: Or Control and Communication in the Animal and the Machine, 2nd edition, Cambridge Massechuses: MIT Press.

Yan, Y. J. and Zhang, B. W. (2011). “On dividing development stages of human substance civilization into six ages”, Journal of South China University of Technology 13 (6): 101-109.

Zhang, B. W. (2009). Physical fundamental of nanomaterials, Beijing: Press of Chemical Industry. This book was published in English, Elsevier Press, 2018. The four English translators: Zhang, Heng; Tan, Zhaosheng; Wu, Lijun; Men, Zhaochen.

Zhang, B. W. and Yan, Y. J. (2011). “On the Substance of Civilization in Human Society Entering into the Nanomaterials Age”, Arts and Social Sciences Journal ASSJ-28: 1-12.

Zhang, B. W. (2012).“On Typical Materials Acting as the Dividing Standard of the Development Stages of human Substance Civilization”, Interdisciplinary Description of Complex Systems 10 (2): 114-126.

Zhang, B. W. (2019).“On Development of Information Communications in Human Society”, Submitted to Social Sciences in China (in English).

Zhong, Y. X. (2002). Principle of Cybernetics Sciences, 3rd Ed. Beijing: Publication Press of Beijing University of Post and Telecommunications. 